\title{
Crescimento, digestibilidade e resistência à infecção por patógeno em tilápia-do-nilo alimentada com probióticos
}

\author{
Fernando Henrique Gomes Cornélio(1), Eduardo Cargnin-Ferreira ${ }^{(2)}$, Maude Regina de Borba(3), \\ José Luiz Pedreira Mouriño(1), Vitor Augusto Giatti Fernandes ${ }^{(1)}$ e Débora Machado Fracalossi(1)
}

\begin{abstract}
(1)Universidade Federal de Santa Catarina, Departamento de Aquicultura, Rodovia Admar Gonzaga, no 1.346, CEP 88034-001 Florianópolis, SC. E-mail: fernando_cornelio@hotmail.com, mourino@lcm.ufsc.br, vitor.giatti@gmail.com, deboraf@cca.ufsc.br (2)Instituto Federal de Educação, Ciência e Tecnologia de Santa Catarina, Laboratório de Marcadores Histológicos, Campus Garopaba, Rodovia SC 434, Km 11, no 11.090, Campo D'Una, CEP 88495-000 Garopaba, SC. E-mail: eduardo.cargnin@ifsc.edu.br (3)Universidade Federal da Fronteira Sul, Campus Laranjeiras do Sul, Rua Oscar da Silva Guedes, no 01, Vila Alberti, CEP 85303-775 Laranjeiras do Sul, PR. E-mail: maude.borba@uffs.edu.br
\end{abstract}

Resumo - O objetivo deste trabalho foi avaliar o efeito da suplementação da dieta com os probióticos Lactobacillus plantarum e Saccharomyces cerevisiae, no desempenho zootécnico, digestibilidade e na resistência à infecção por patógeno, em alevinos de tilápia-do-nilo. Foram realizados três ensaios. No primeiro, durante 55 dias, seis grupos de 30 alevinos $(2,4 \pm 0,5 \mathrm{~g})$ receberam suplementação com probióticos, e outros três grupos não receberam suplementação. No final desse período, no segundo ensaio, os peixes foram desafiados com Aeromonas hydrophila, e a sobrevivência foi avaliada por 96 horas. No terceiro ensaio, com oito peixes por tanque $(230,0 \pm 10,0 \mathrm{~g})$, avaliou-se a digestibilidade da dieta após a suplementação com os probióticos. A suplementação probiótica melhora significativamente o ganho de peso, a conversão alimentar, as taxas de retenção proteica e energética, assim como a resistência dos animais a Aeromonas hydrophila, após a infecção. A suplementação com Saccharomyces cerevisiae à dieta de tilápia-do-nilo melhora significativamente a digestibilidade da proteína, energia e matéria seca.

Termos para indexação: Aeromonas hydrophila, Lactobacillus plantarum, Oreochromis niloticus, Saccharomyces cerevisiae, desempenho produtivo, nutrição.

\section{Growth, digestibility and resistance to pathogen infection in Nile tilapia fed with probiotics}

\begin{abstract}
The objective of this work was to evaluate the effect of dietary supplementation with probiotics Lactobacillus plantarum and Saccharomyces cerevisiae on the performance, resistance to pathogen infection and digestibility in Nile tilapia fingerlings. Three trials were performed. In the first one, six groups of 30 fingerlings $(2.4 \pm 0.5 \mathrm{~g})$ received supplementation with probiotics during 55 days, and other three groups received no supplementation. At the end of this period, in the second trial, fish were challenged with Aeromonas hydrophila, and survival was assessed over 96 hours. In the third trial, with eight fish per tank $(230,0 \pm 10,0 \mathrm{~g})$, diet digestibility after the probiotic supplementation was evaluated. Supplementation with probiotics significantly improves weight gain, feed conversion, and protein and energy retention rates, as well as the resistance to Aeromonas hydrophila after infection. Supplementation of Saccharomyces cerevisiae to the diet of Nile tilapia significantly improves the digestibility of protein, energy, and dry matter.
\end{abstract}

Index terms: Aeromonas hydrophila, Lactobacillus plantarum, Oreochromis niloticus, Saccharomyces cerevisiae, productive performance, nutrition.

\section{Introdução}

Há crescente evidência de que a suplementação com probióticos pode apresentar efeito benéfico sobre a microbiota intestinal de peixes e, assim, tornar-se uma importante ferramenta para reduzir a ocorrência de patógenos e melhorar o crescimento (Suzer et al., 2008). A inclusão de probióticos na produção animal objetiva estabilizar uma determinada população bacteriana em condições ideais de normalidade
(Jones, 1991) e favorecer o desempenho zootécnico dos animais, bem como atenuar os desafios presentes no ambiente de criação. Portanto, a aplicação de probióticos pode representar uma excelente alternativa ao uso de antibióticos e quimioterápicos, os quais podem causar problemas econômicos, sanitários e ambientais. Vários estudos relatam o efeito positivo do uso de probióticos na avicultura (Correa et al., 2002), suinocultura (Huaynate et al., 2006) e, mais 
recentemente, na piscicultura (Suzer et al., 2008) e carcinicultura (Vieira et al., 2010).

Vários microrganismos podem ser utilizados como probióticos, especialmente as bactérias acidolácticas e a levedura Saccharomyces cerevisiae (Ringo et al., 2010). O uso desses microrganismos como suplemento probiótico, na dieta de organismos aquáticos, tem mostrado efeito benéfico, por melhorar o crescimento, a utilização dos nutrientes, a resistência aos patógenos e aumentar a atividade de enzimas digestivas, com consequente melhoria no aproveitamento da ração pelo hospedeiro (Verschuere et al., 2000; Ortuño et al., 2002; Wang \& Xu, 2006; Hisano et al., 2007)

O modo de ação dos probióticos, na microflora intestinal, ainda não é completamente entendido; porém, estudos sugerem que isto pode ocorrer por meio da competição por sítios de ligação na parede intestinal, produção de inibidores, competição por nutrientes e energia, ou pelo estímulo do sistema imunitário (Balcázar et al., 2006). Assim, é importante que se realizem novos estudos com esses microrganismos benéficos, principalmente, para tentar amenizar doenças bacterianas, um dos fatores que mais prejudica o cultivo de peixes.

Entre essas doenças, destaca-se a infecção por Aeromonas hydrophila, bactéria causadora de mortalidade em massa a várias espécies (Abdel-Tawwab et al., 2008). No entanto, há poucos estudos na literatura sobre o efeito da suplementação de probióticos na dieta e sobre a utilização do alimento, inclusive sobre a digestibilidade dos nutrientes (Merrifield et al., 2010; Ringo et al., 2010). Entretanto, a possibilidade de aumento do ganho de peso e da utilização dos nutrientes, em adição ao aumento já conhecido da resistência à infecção causada por agentes patogênicos, seria um incentivo adicional para uso da suplementação de probióticos na aquicultura, principalmente em tilápia, que é uma das espécies de maior importância.

O objetivo deste trabalho foi avaliar o efeito da suplementação da dieta com os probióticos Lactobacillus plantarum e Saccharomyces cerevisiae, no desempenho zootécnico, resistência à infecção por patógeno e digestibilidade, em alevinos de tilápia-do-nilo.

\section{Materiais e Métodos}

Três ensaios - crescimento, desafio com patógeno e digestibilidade - foram realizados no Laboratório de Biologia e Cultivo de Peixes de Água Doce (Lapad), da Universidade Federal de Santa Catarina (UFSC), em Florianópolis, SC. Todos os ensaios foram realizados conforme o protocolo PP00815, aprovado pela Comissão de Ética no Uso de Animais, da UFSC.

O primeiro ensaio, com duração de 55 dias, teve o objetivo de avaliar o crescimento, a conversão alimentar e a retenção de proteína e energia da dieta, em alevinos de tilápia-do-nilo, com ou sem a suplementação de dois probióticos: a bactéria Lactobacillus plantarum e a levedura Saccharomyces cerevisiae.

A suplementação da dieta com Lactobacillus plantarum 22708 Cpqba DRM, isolada do intestino da tilápia-donilo e identificada bioquimicamente com o kit API 50 (BioMérieux, Lyon, France) (Jatobá et al., 2008), foi realizada por aspersão de um meio de cultura, com 1 x $10^{8}$ UFC $\mathrm{mL}^{-1}$ (unidades formadoras de colônia), a uma dieta comercial extrusada à proporção de $100 \mathrm{~mL} \mathrm{~kg}^{-1}$. A dieta suplementada foi incubada a $35^{\circ} \mathrm{C}$ por 24 horas, em sacos hermeticamente fechados. Após a incubação, a dieta foi seca a $35^{\circ} \mathrm{C}$ por 24 horas. A dieta controle, sem probiótico, passou pelo mesmo procedimento, mas foi aspergida somente com água. A suplementação com levedura foi realizada na água. Assim, a levedura seca $(0,5 \mathrm{~g})$ era submetida a um processo de ativação, que consistia de sua imersão em água morna a $35^{\circ} \mathrm{C}$, com açúcar $(0,25 \mathrm{~g})$, durante uma hora, sob aeração. Após a ativação, a levedura era submetida a um processo de expansão e reprodução, com duração de 24 horas, e uma fonte de carboidrato (10 g melaço) era adicionada à solução inicial. Semanalmente, durante todo o período experimental, $0,5 \mathrm{~L}$ dessa solução era adicionado à água dos tanques cujo tratamento era a suplementação com levedura.

Foi feita a quantificação quinzenal tanto da levedura na água quanto da bactéria na ração, durante todo o período experimental, e as médias foram 1,0 x $10^{8} \mathrm{UFC} \mathrm{g}^{-1} \mathrm{de}$ Lactobacillus plantarum na dieta e 5,6 x $10^{5}{\mathrm{UFC} \mathrm{mL}^{-1} \mathrm{de}}$ Saccharomyces cerevisiae na água. A quantificação da bactéria foi realizada por meio de diluições de $10^{3}, 10^{4} \mathrm{e}$ $10^{5}$, em meio de cultura, com posterior contagem (UFC g ${ }^{-1}$ de ração). A quantificação da levedura foi realizada conforme Tournas et al. (2001).

Neste primeiro ensaio, avaliou-se o crescimento de 180 alevinos, selecionados de um lote inicial de 1.000 peixes, da espécie Oreochromis niloticus, com peso inicial de 2,4 $\pm 0,5 \mathrm{~g}$ (média_desvio padrão), provenientes de uma piscicultura comercial. Os peixes foram estocados em nove tanques, com volume de $120 \mathrm{~L}$, à densidade de 30 peixes por tanque, e foram aclimatados às condições experimentais por uma semana. Durante 55 dias, seis grupos de 30 peixes foram submetidos ao condicionamento 
em água com o probiótico, dos quais três receberam a suplementação na dieta, e três que formaram o grupo controle, não receberam nenhuma suplementação.

Os tanques que receberam o condicionamento com o probiótico na água possuíam sistemas individuais de recirculação, enquanto os tanques com suplementação na dieta e os tanques sem suplementação estavam conectados a um sistema central de recirculação de água do laboratório. Todos os tanques receberam aeração constante, e o oxigênio dissolvido na água e a temperatura foram monitorados diariamente, com auxílio de oxímetro, enquanto o pH e a amônia total, semanalmente, por meio de kits comerciais específicos. Durante o experimento, o fotoperíodo foi de 12 horas, a temperatura variou em $28,0 \pm 0,5^{\circ} \mathrm{C}$, e o oxigênio em $6,00 \pm 0,5 \mathrm{mg} \mathrm{L}^{-1}$. As variáveis indicadoras da qualidade da água foram mantidas em níveis aceitáveis para o cultivo de tilápias (Popma \& Lovshin, 1994).

Os peixes foram pesados a cada 10 dias aproximadamente, para avaliação de ganho de peso, conversão alimentar e ajuste da taxa alimentar, que foi gradativamente reduzida de $7 \%$ da biomassa de cada tanque por dia, ao início do experimento, para $5 \%$ da biomassa, ao final (Kubitza, 2011). A ração comercial $(41,6 \%$ de proteína bruta) foi fornecida três vezes ao dia: às 8,13 e $18 \mathrm{~h}$.

Para a determinação da composição corporal inicial, duas amostras de 20 peixes $(2,4 \pm 0,5 \mathrm{~g})$ foram selecionadas do lote inicial. Os peixes foram sacrificados, triturados e homogeneizados; uma alíquota de aproximadamente $80 \mathrm{~g}$ foi retirada para as análises de proteína bruta, energia bruta e matéria seca. $\mathrm{O}$ mesmo procedimento foi adotado para análise da composição final dos peixes, tendo-se retirado uma amostra de dois peixes, por tanque, ao final do ensaio alimentar.

As equações utilizadas na avaliação de desempenho zootécnico e retenção de nutrientes foram as seguintes: ganho de peso $(\mathrm{GP})=$ peso final - peso inicial; taxa de crescimento específico $(\mathrm{TCE})=100 \times[(\ln$ peso final - In peso inicial)/número de dias]; fator de conversão alimentar (FCA) = alimento consumido / GP; taxa de retenção proteica $($ TRP $)=[($ peso final $\times$ proteína corporal final) (peso inicial $\times$ proteína inicial corporal) $/$ proteína total ingerida] $\times 100$; taxa de retenção energética (TER) $=[$ peso final $\times$ energia corporal final) $($ peso inicial $\times$ energia corporal inicial) / energia total ingerida] $\times 100$.

No segundo ensaio, logo após o ensaio de crescimento, os peixes foram submetidos a um desafio com a bactéria patogênica Aeromonas hydrophila Cpqba 22808 DRM, para avaliação da resistência à infecção. Os peixes $(n=26)$ de cada unidade experimental foram subdivididos em dois grupos de igual número $(\mathrm{n}=13)$ : o primeiro grupo recebeu, por injeção intraperitoneal, $0,4 \mathrm{~mL}$ de uma solução que continha o patógeno Aeromonas hydrophila ( $10^{7}$ células $\left.\mathrm{mL}^{-1}\right)$; e o segundo grupo permaneceu como controle da infecção, por meio de injeção intraperitoneal de $0,4 \mathrm{~mL}$ de solução salina. Esse volume de solução com o patógeno representava a dose letal média $\left(\mathrm{DL}_{50}\right)$, determinada em pré-ensaio, feito no próprio laboratório, com base na metodologia proposta por Silva et al. (2012). Os peixes ficaram em observação durante 96 horas, quando foram registrados os sinais clínicos e a mortalidade.

No terceiro ensaio, os coeficientes de digestibilidade aparente da proteína, energia e matéria seca foram determinados com os mesmos probióticos utilizados no ensaio de crescimento. Três grupos de peixes receberam a ração comercial (40,5\% de proteína bruta), suplementada com a bactéria, três receberam a ração suplementada com a levedura, e outros três, a ração sem suplementação (controle). Cada grupo experimental foi constituído por oito peixes, com peso médio de $230 \pm 10 \mathrm{~g}$, oriundos de uma piscicultura comercial, os quais foram aleatoriamente distribuídos em nove tanques cilíndrico-cônicos, com volume de 200 L. A preparação da suplementação das rações foi feita de acordo com o primeiro ensaio, porém, a suplementação com levedura foi realizada via aspersão. Acontagem de microrganismosresultouna concentração de $4,0 \times 10^{5} \mathrm{UFC} \mathrm{g}^{-1}$ de levedura e $1,0 \times 10^{8} \mathrm{UFC} \mathrm{g}^{-1} \mathrm{de}$ bactéria, confirmadas pela quantificação em laboratório, tendo-se utilizado a mesma metodologia descrita anteriormente. Estes tanques estavam acoplados a um sistema de recirculação de água, com troca parcial de 10 a $15 \mathrm{~L} \mathrm{~min}^{-1}$, equipado com aeração e controle de temperatura $\left(27,0 \pm 0,7^{\circ} \mathrm{C}\right)$. A qualidade da água foi monitorada pela determinação diária do oxigênio dissolvido e temperatura com oxímetro, bem como pela medida semanal do $\mathrm{pH}$ e concentração de amônia total, por meio de kits específicos.

Foi utilizado o método indireto na determinação da digestibilidade, com o uso de $0,5 \%$ de óxido de crômio como indicador na ração. A coleta de fezes foi feita após sedimentação em tanques cilindro-cônicos de $200 \mathrm{~L}$, equipados com tubo coletor $(50 \mathrm{~mL})$ no fundo de cada tanque. Durante a coleta das fezes, os tubos ficavam dentro de caixas de isopor com gelo, para evitar a degradação das fezes. As coletas foram feitas duas vezes ao dia, a intervalos de 6 horas ( 24 h e $6 \mathrm{~h}$ ), durante quatro semanas, até atingir $10 \mathrm{~g}$ de matéria seca para cada tanque. A metodologia de coleta de fezes foi a mesma 
descrita por Kitagima \& Fracalossi (2010), com apenas uma modificação: os animais permaneceram nos mesmos tanques durante a alimentação e a coleta de fezes. Cada coleta de fezes era precedida de uma limpeza rigorosa das paredes do tanque, bem como de uma troca de $90 \%$ da água, para evitar contaminação das fezes com restos de ração e filme bacteriano formado nas paredes dos tanques. Os tubos coletores que continham as fezes resultantes das coletas eram submetidos à centrifugação a $2.296 \times g$ por $5 \mathrm{~min}$. O líquido sobrenadante foi descartado, e as fezes secas em estufa $\left(50^{\circ} \mathrm{C}\right)$ até peso constante. Após esse período, as fezes foram trituradas e congeladas a $20^{\circ} \mathrm{C}$ para análise posterior.

Os peixes foram alimentados com as dietas experimentais três vezes ao dia - às 8,12 e $16 \mathrm{~h}$-, com uma quantidade de ração equivalente a $3 \%$ do peso vivo para cada tanque (Kubitza, 2011). A concentração do marcador, óxido de crômio, foi medida na ração, assim como nas fezes, para estimar o coeficiente de digestibilidade aparente da matéria seca, proteína bruta e energia da ração comercial com ou sem as suplementações dos probióticos.

A análise da composição proximal das rações comerciais, utilizadas no ensaio de crescimento e no ensaio de digestibilidade, foi realizada no laboratório de Nutrição de Espécies Aquícolas (Labnutri, Ufsc), conforme procedimentos descritos pela Association of Official Analitycal Chemists (Cunniff, 1995) (Tabela 1).

Os coeficientes de digestibilidade aparente (CDA) foram calculados pelas seguintes equações: $\mathrm{CDA}_{\text {matéria seca }}=100 \quad\left[100 \times\left(\mathrm{Cr}_{2} \mathrm{O}_{3}\right.\right.$ dieta $/ \mathrm{Cr}_{2} \mathrm{O}_{3}$ fezes $\left.)\right] \mathrm{e}$;

Tabela 1. Composição proximal das rações comerciais ${ }^{(1)}$, utilizadas no ensaio de crescimento e no ensaio de digestibilidade de nutrientes para tilápia-do-nilo, Oreochromis niloticus.

\begin{tabular}{lcc}
\hline Fração & \multicolumn{2}{c}{ Ensaios } \\
\cline { 2 - 3 } & Crescimento & Digestibilidade \\
\hline Umidade (\%) & 7,00 & 9,46 \\
Proteína bruta (\%) & 41,60 & 40,50 \\
Matéria mineral (\%) & 10,31 & 10,27 \\
Extrato etéreo (\%) & 7,50 & 7,49 \\
Fibra em detergente ácido (\%) & 5,08 & 5,86 \\
Energia bruta (kcal kg-1) & 4.021 & 4.128 \\
\hline
\end{tabular}

${ }^{(1)}$ Nicoluzzi Rações, Penha, SC, Brazil. Níveis de garantia fornecidos pelo fabricante por quilograma de ração: umidade, 11\%; proteína bruta, 36\%; extrato etéreo, $7 \%$; fibra bruta, $6 \%$; matéria mineral, $12 \%$; cálcio, 2\%; fósforo, 0,7\%; ácido fólico, 2,5 g; ácido pantotênico, 28,6 mg; biotina, 0,2 mg; cobalto, 0,05 mg; cobre, 5,0 mg; ferro, 60,0 mg; iodo, 1,1 mg; manganês, 13,0 mg; niacina, 20,0 mg; selênio, 0,3 mg; vitamina A, 4.168.000 $\mathrm{UI}$; vitamina B6 5,0 g; vitamina C, 245,0 mg; vitamina D3, $2.668 \mathrm{UI}$; vitamina E, 100,0 mg; vitamina K3, 8,8 mg; zinco, 100,0 mg.
$\mathrm{CDA}_{\text {proténa, energia }}=100\left[100 \times\left(\mathrm{Cr}_{2} \mathrm{O}_{3 \text { dieta }} / \mathrm{Cr}_{2} \mathrm{O}_{3}\right.\right.$ fezes $) \times$ (nutriente nas fezes / nutriente na dieta)], de acordo com Belal (2005) e Nose (1960), respectivamente.

Foram coletadas amostras do intestino anterior, médio e posterior de dois peixes por tanque, de cada tratamento $(n=6)$, tanto no ensaio de crescimento quanto no ensaio de digestibilidade, para confirmação da presença da levedura e da bactéria no trato gastrointestinal, bem como para detectar possíveis alterações morfológicas ocasionadas pela adição dos probióticos. As amostras foram fixadas em formol tamponado com fosfato $0,1 \mathrm{~mol} \mathrm{~L}^{-1}$ e $\mathrm{pH} 7,2$, durante um mínimo de 48 horas. Posteriormente, foram lavadas em água corrente durante duas horas. Depois de cuidadosa desidratação em etanol, utilizou-se a metodologia de rotina (Cargnin-Ferreira \& Sarasquete Reiriz, 2008), para a inclusão em parafina a $58{ }^{\circ} \mathrm{C}$, tendose utilizado o xilol como líquido intermediário. Após a inclusão do material em parafina, os blocos resultantes foram cortados em micrótomo Leica RM 2025. Os cortes, com espessura de $5 \mu \mathrm{m}$, foram então estirados e recolhidos em banho termostático a $52{ }^{\circ} \mathrm{C}$ e dispostos sobre lâminas gelatinizadas. Os cortes foram desparafinizados, hidratados conforme a metodologia de rotina e corados com a técnica tricrômica de Cason (Cargnin-Ferreira \& Sarasquete Reiriz, 2008).

Todos os dados obtidos nos ensaios de crescimento, desafio e digestibilidade foram submetidos à análise de variância. As médias do tratamento foram comparados pelo teste Tukey, a 5\% de probabilidade.

\section{Resultados e Discussão}

Não houve mortalidade nos ensaios de crescimento e digestibilidade. Os peixes que receberam suplementação, tanto com $S$. cerevisiae na água, quanto com L. plantarum na ração, apresentaram aumento significativo de ganho de peso, conversão alimentar, retenção proteica e energética; no entanto, a taxa de crescimento específico não foi afetada (Tabela 2).

Estes resultados estão de acordo com outros estudos sobre suplementação de probióticos para tilápias, que mostram efeitos benéficos na resposta imune e no crescimento, após suplementação com bactérias acidoláticas (Aly et al., 2008a, 2008b; Wang et al., 2008) ou após suplementação com leveduras (Meurer et al., 2000; Lara-Flores et al., 2003; Pezzato et al., 2006; Hisano et al., 2007; Abdel-Tawwab et al., 2008). Conforme relatado por Gatesoupe (1999) e Ziemer \& Gibson (1998), os efeitos no desempenho (ganho 
de peso, conversão alimentar, retenção de nutrientes) dos animais suplementados podem ser atribuídos à melhoria da atividade digestiva como um todo, por meio do aumento da síntese de vitaminas, cofatores e atividades enzimáticas, o que favorece a digestão, absorção de nutrientes e consequentemente o ganho em peso.

As suplementações probióticas também proporcionaram aumento da resistência da tilápia após a infecção pelo patógeno Aeromonas hydrophila (Figura 1). Não houve mortalidade de peixes que receberam injeção apenas da solução salina (grupo-controle). Porém, nos peixes infectados, a mortalidade diminuiu significativamente após 96 horas. A redução foi de: 56\% no tratamentocontrole, sem suplementação; $30 \%$, com a suplementação da bactéria na ração; e 33\%, com a suplementação da levedura na água. Esses resultados mostram que tanto a levedura quanto a bactéria promoveram aumento de resistência da tilápia à infecção por patógeno. Alguns possíveis mecanismos de ação dos probióticos, para aumento de resistência após infecção, foram descritos por Balcázar et al. (2008), em estudo com truta arco-íris (Onchorrynchus mykiss). Os autores verificaram que os microrganismos probióticos mostraram grande habilidade de aderir ao muco intestinal, o que causou significativa redução de adesão de patógenos, e sugeriram que há possibilidade de secreção de substâncias antimicrobianas pelos microrganismos probióticos, além da exclusão por competição de nutrientes.

No ensaio de digestibilidade, apenas a suplementação da ração comercial com a levedura Saccharomyces cerevisiae propiciou significativa melhoria de digestibilidade da matéria seca, proteína bruta e energia

Tabela 2. Valores médios de ganho de peso, fator de conversão alimentar, crescimento específico e taxa de retenção proteica e energética, em alevinos de tilápiado-nilo (Oreochromis niloticus), mantidos com ou sem suplementação de probióticos (Saccharomyces cerevisiae na água ou Lactobacillus plantarum na ração), durante 55 dias $^{(1)}$.

\begin{tabular}{lrrr}
\hline Variável & Controle & \multicolumn{2}{c}{ Suplementação com probiótico } \\
\cline { 3 - 4 } & & S. cerevisiae & L. plantarum \\
\hline Ganho de peso $(\mathrm{g})$ & $21,70 \pm 0,81 \mathrm{~b}$ & $23,60 \pm 0,22 \mathrm{a}$ & $23,5 \pm 0,19 \mathrm{a}$ \\
Fator de conversão alimentar & $1,34 \pm 0,03 \mathrm{~b}$ & $1,28 \pm 0,01 \mathrm{a}$ & $1,27 \pm 0,02 \mathrm{a}$ \\
Taxa de crescimento específico (\%) & $4,25 \pm 0,10 \mathrm{a}$ & $4,36 \pm 0,04 \mathrm{a}$ & $4,33 \pm 0,01 \mathrm{a}$ \\
Taxa de retenção proteica (\%) & $27 \pm 0,90 \mathrm{~b}$ & $29,5 \pm 0,62 \mathrm{a}$ & $29,87 \pm 1,28 \mathrm{a}$ \\
Taxa de retenção energética (\%) & $22,5 \pm 0,42 \mathrm{~b}$ & $24,4 \pm 0,38 \mathrm{a}$ & $24,8 \pm 0,42 \mathrm{a}$ \\
\hline
\end{tabular}

${ }^{(1)}$ Médias seguidas por letras iguais, nas linhas, não diferem, pelo teste de Tukey, a $5 \%$ de probabilidade. bruta para tilápia-do-nilo (Tabela 3). Estes resultados concordam com aqueles relatados sobre tilápias da mesma espécie, por Lara-Flores et al. (2003) e Hisano et al. (2008), mas com peso menor (152 g e $83 \mathrm{~g}$, respectivamente) que os peixes utilizados no presente estudo (230 g). Alguns autores sugerem que a melhoria da digestibilidade ocorre em consequência da presença de nutrientes (vitaminas) e enzimas no probiótico, o que pode favorecer o aproveitamento dos nutrientes pelos peixes (Gatesoupe, 1999; Ziemer \& Gibson, 1998).

Não foi observada qualquer alteração morfológica nos intestinos dos peixes, nos ensaios nas preparações histológicas. A análise das imagens constatou a presença de células de $S$. cerevisiae, bem como aumento da população de bactérias, possivelmente L. plantarum, no trato gastrointestinal dos peixes que receberam as respectivas suplementações, tanto no ensaio de crescimento quanto no ensaio de digestibilidade (Figura 2). Isto mostra a inocuidade e a capacidade de adesão e fixação desses dois microrganismos no trato dos animais. Essas características são imprescindíveis para que um microrganismo seja considerado um bom probiótico (Balcázar et al., 2006).

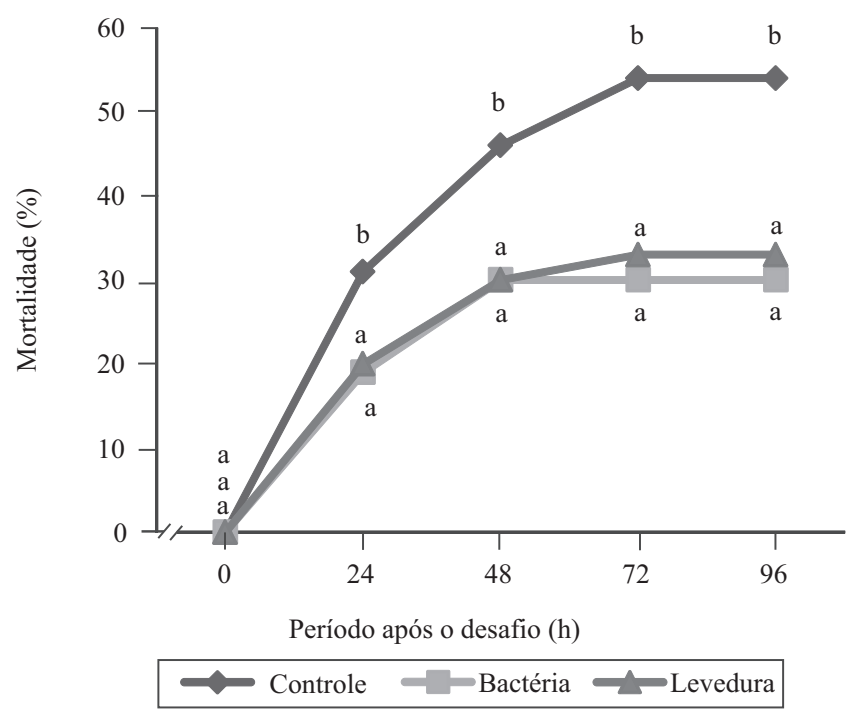

Figura 1. Mortalidade acumulada de alevinos de tilápiado-nilo, criados com ou sem suplementação de probióticos (S. cerevisiae e L. plantarum) por 55 dias, após desafio com o patógeno Aeromonas hydrophila. Letras diferentes, entre os diferentes tempos de infecção, para cada tratamento, diferem pela análise de variância, a 5\% de probabilidade. 
Tabela 3. Média dos coeficientes de digestibilidade aparente de proteína, matéria seca e energia bruta, de uma ração comercial com ou sem suplementação dos probióticos Saccharomyces cerevisiae ou Lactobacillus plantarum, para alevinos de tilápia-do-nilo ${ }^{(1)}$.

\begin{tabular}{lccc}
\hline Variável & Controle & \multicolumn{2}{c}{ Suplementação com probióticos } \\
\cline { 3 - 4 } & & S. cerevisiae & L. plantarum \\
\hline Matéria seca & $70,5 \pm 1,10 \mathrm{~b}$ & $74,3 \pm 1,50 \mathrm{a}$ & $72,8 \pm 0,70 \mathrm{~b}$ \\
Proteína & $83,5 \pm 0,67 \mathrm{~b}$ & $85,4 \pm 0,48 \mathrm{a}$ & $84,8 \pm 0,45 \mathrm{~b}$ \\
Energia & $77,0 \pm 2,20 \mathrm{~b}$ & $81,4 \pm 0,70 \mathrm{a}$ & $78,6 \pm 0,10 \mathrm{~b}$ \\
\hline
\end{tabular}

${ }^{(1)}$ Médias seguidas por letras iguais, nas linhas, não diferem pelo teste de Tukey, a $5 \%$ de probabilidade.
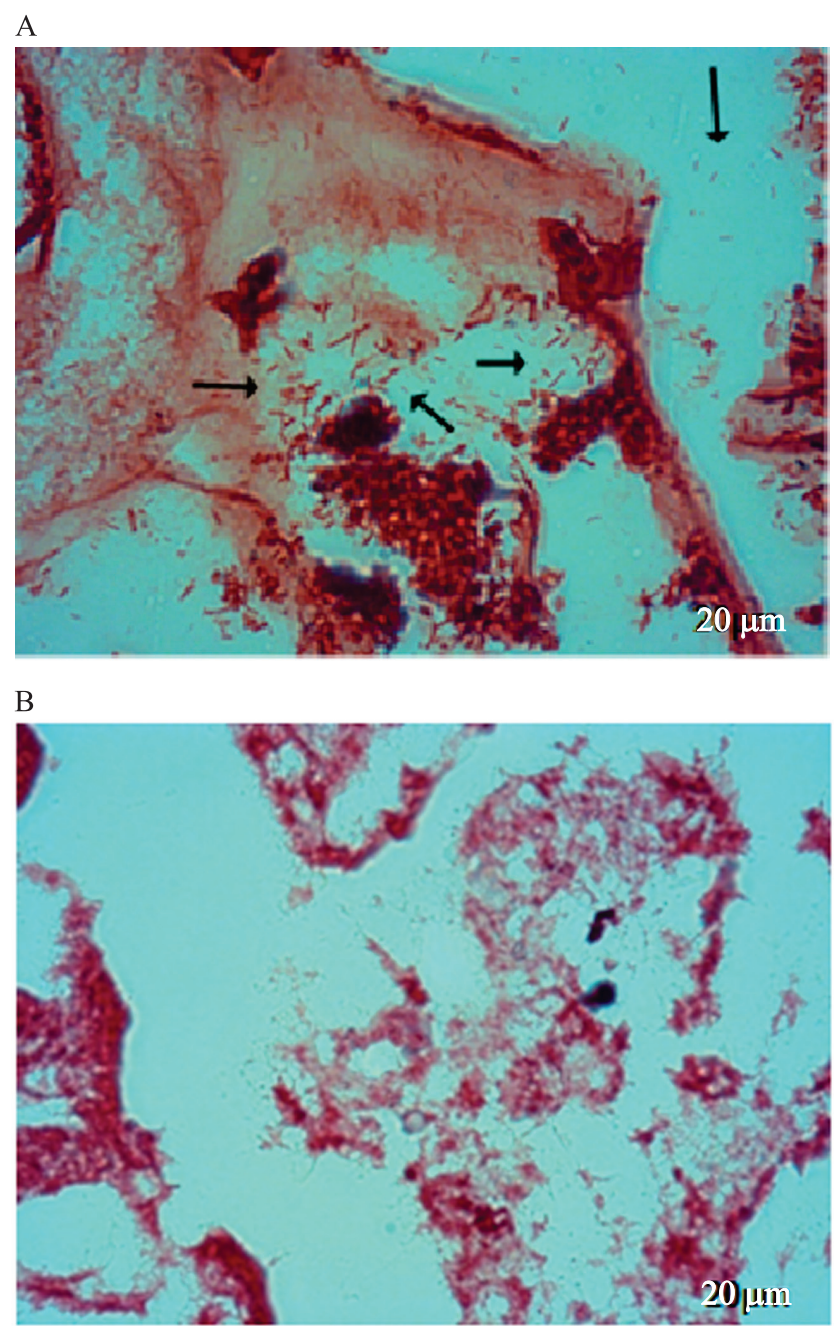

Figura 2. Preparação histológica típica do lúmen intestinal de alevinos de tilápia-do-nilo, alimentados com dietas suplementadas (A) ou não (B) com probiótico Lactobacillus plantarum $(1000 \times)$. Setas indicam grupos de filamentos celulares, provavelmente da bactéria probiótica Lactobacillus plantarum.

\section{Conclusões}

1. A suplementação probiótica, tanto com a bactéria Lactobacillus plantarum na ração, quanto com a levedura Saccharomyces cerevisiae na água, melhoram o desempenho zootécnico e a resistência de alevinos de tilápia-do-nilo à infecção pelo patógeno Aeromonas hydrophila .

2. A suplementação dietética com o probiótico Saccharomyces cerevisiae melhora a digestibilidade de energia, proteína e matéria seca da dieta.

3. A suplementação dietética com o probiótico Lactobacillus plantarum não afeta a digestibilidade da energia, proteína e matéria seca da dieta.

\section{Agradecimentos}

Ao Ministério da Pesca e Aquicultura (MPA) e à Empresa Brasileira de Pesquisa Agropecuária (Embrapa), Projeto Aquabrasil, pelo apoio financeiro; ao Conselho Nacional de Desenvolvimento Científico e Tecnológico (CNPq), pela concessão de bolsas.

\section{Referências}

ABD-EL-TAWWAB, M.; ABD-EL-RAHMAN, A.M.; ISMAEL, N.E.M. Evaluation of commercial live bakers' yeast, Saccharomyces cerevisiae, as a growth and immunity promoter for Fry Nile tilapia, Oreochromis niloticus (L.) challenged in situ with Aeromonas hydrophila. Aquaculture, v.280, p.185-189, 2008. DOI: 10.1016/j.aquaculture.2008.03.055.

ALY, S.M.; ABD-EL-RAHMAN, A.M.; JOHN, G.; MOHAMED, M.F. Characterization of some bacteria isolated from Oreochromis niloticus and their potential use as probiotics. Aquaculture, v.277, p.1-6, 2008a. DOI: 10.1016/j.aquaculture.2008.02.021.

ALY, S.M.; AHMED, Y.A.G.; GHAREEB, A.A.A.; MOAHMED, M.F. Studies on Bacillus subtilis and Lactobacillus acidophilus, as potential probiotics, on the immune response and resistance of Tilapia nilotica (Oreochromis niloticus) to challenge infections. Fish and Shellfish Immunology, v.25, p.128-136, 2008b. DOI: 10.1016/j.fsi.2008.03.013.

BALCÁZAR, J.L.; DE BLAS, I.; RUIZ-ZARZUELA, I.; CUNNINGHAM, D.; VENDRELL, D.; MÚZQUIZ, J.L. The role of probiotics in aquaculture. Veterinary Microbiology, v.114, p.173-186, 2006. DOI: 10.1016/j.vetmic.2006.01.009.

BALCÁZAR, J.L.; VENDRELL, D.; BLAS, I. de; RUIZZARZUELA, I.; MUZQUIZ, J.L.; GIRONES, O. Characterization of probiotic properties of lactic acid bacteria isolated from intestinal microbiota of fish. Aquaculture, v.278, p.188-191, 2008. DOI: 10.1016/j.aquaculture.2008.03.014. 
BELAL, I.E.H. A review of some fish nutrition methodologies. Bioresourse Technology, v.96, p.395-402, 2005. DOI: 10.1016/j. biortech.2003.11.030.

CARGNIN-FERREIRA, E.; SARASQUETE REIRIZ, M. del C. Histofisiología de moluscos bivalvos marinos. Madrid: Consejo Superior de Investigaciones Cientificas, 2008. 94p.

CORREA, G. da S.S.; GOMES, A.V. da C.; CORRÊA, A.B.; SALLES, A. da S.; FERNANDO, A.C. Digestibilidade da ração de frangos de corte suplementados com probióticos e antibiótico. Ciência Rural, v.32, p.687-691, 2002. DOI: 10.1590/S010384782002000400023.

CUNNIFF, P. (Ed.). Official methods of analysis of AOAC international. $16^{\text {th }}$ ed. Gaithersburg: AOAC International, 1995. $2 \mathrm{v}$.

GATESOUPE, F.J. The use of probiotics in aquaculture. Aquaculture, v.180, p.147-165, 1999. DOI: 10.1016/ S00448486(99)001878.

HISANO, H.; NARVÁEZSOLARTE, W.V.; BARROS, M.M.; PEZZATO, L.E. Desempenho produtivo de alevinos de tilápiado-nilo alimentados com levedura e derivados. Pesquisa Agropecuária Brasileira, v.42, p.1035-1042, 2007. DOI: 10.1590/ S0100204X2007000700017.

HISANO, H.; SAMPAIO F.G.; BARROS, M.M.; PEZZATO, L.E. Digestibilidade aparente de rações contendo levedura íntegra, levedura autolisada e parede celular pela tilápia-do-nilo. Boletim do Instituto de Pesca, v.34, p.281-287, 2008.

HUAYNATE, R.A.R.; THOMAZ, M.C.; KRONKA, R.N.; FRAGA, A.L.; SCANDOLERA, A.J.; BUDIÑO, F.E.L. Uso de probiótico em dietas de suínos: incidência de diarreia, desempenho zootécnico e digestibilidade de rações. Brazilian Journal of Veterinary Research and Animal Science, v.43, p.664-673, 2006.

JATOBÁ, A.; VIEIRA, F. do N.; BUGLIONENETO, C.; SILVA, B.C.; MOURIÑO, J.L.P.; JERÔNIMO, G.T.; DOTTA, G.; MARTINS, M.L. Utilização de bactérias acidolácticas isoladas do trato intestinal de tilápia-do-nilo como probiótico. Pesquisa Agropecuária Brasileira, v.43, p.1201-1207, 2008. DOI: 10.1590/ S0100204X2008000900015.

JONES, F.T. Use of directfed microbials not new, way the work still not clear. Feedstuffs, v.63, p.17-19, 1991.

KITAGIMA, R.E.; FRACALOSSI, D.M. Validation of a methodology for measuring nutrient digestibility and evaluation of commercial feeds for channel catfish. Scientia Agricola, v.67, p.611-615, 2010. DOI: 10.1590/S010390162010000500016.

KUBITZA, F. Tilápia: tecnologia e planejamento na produção comercial. 2.ed. rev. ampl. Jundiaí: Acqua Supre Com. Suprim. Aqüicultura, 2011. 316p.

LARA-FLORES, M.; OLVERA-NOVOA, M.A.; GUZMÁNMÉNDEZ, B.E.; LÓPEZ-MADRID, W. Use of the bacteria Streptococcus faecium and Lactobacillus acidophilus, and the yeast Saccharomyces cerevisiae as growth promoters in Nile tilapia (Oreochromis niloticus). Aquaculture, v.216, p.193-201, 2003. DOI: 10.1016/S00448486(02)002776.

MERRIFIELD, D.L.; DIMITROGLOU, A.; FOEY, A.; DAVIES, S.J.; BAKER, R.T.M.; BOGWALD, J.; CASTEX, M.; RINGO,
E. The current status and future focus of probiotic and prebiotic applications for salmonids. Aquaculture, v.302, p.1-18, 2010. DOI: 10.1016/j.aquaculture.2010.02.007.

MEURER, F.; HAYASHI, C.; SOARES, C.M.; BOSCOLO, W.R. Utilização de levedura spray dried na alimentação de alevinos de tilápia do Nilo (Oreochromis niloticus L.). Acta Scientiarum, v.22, p.479-484, 2000.

NOSE, T. On the digestion of food proteins by gold fish (Carassius auratus L.) and rainbow trout (Salmo irideus G.). Bulletin of Freshwater Fisheries Research Laboratory, v.10, p.11-22, 1960.

ORTUÑO, J.; CUESTA, A.; RODRÍGUEZ, A.; ESTEBAN, M.A.; MESEGUER, J. Oral administration of yeast, Saccharomyces cerevisiae, enhances the cellular innate immune response of gilthead seabream (Sparus aurata L.). Veterinary Imunnology and Immunopathology, v.85, p.41-50, 2002. DOI: 10.1016/ S01652427(01)004068.

PEZZATO, L.E.; MENEZES, A.; BARROS, M.M.; GUIMARÃES, I.G.; SCHICH, D. Levedura em dietas para alevinos de tilápia do Nilo. Veterinária e Zootecnia, v.13, p.84-94, 2006.

POPMA, T.J.; LOVSHIN, L. Worldwide prospects for commercial production of tilapia. Auburn-Alabama: Auburn University, 1994. 40p.

RINGO, E.; LISBETH, L.; KRISTIANSEN, M.; BAKKEN, Y.; SALINAS, I.; MYKLEBUST, R.; OLSEN, R.E.; MAYHEW, T.M. Lactic acid bacteria vs. pathogens in the gastrointestinal tract of fish: a review. Aquaculture Research, v.41, p.451-467, 2010. DOI: $10.1111 /$ j.13652109.2009.02339.x.

SILVA, B.C. da; MOURIÑO, J.L.P.; VIEIRA, F.N.; JATOBÁ, A.; SEIFFERT, W.Q.; MARTINS, M.L. Haemorrhagic septicaemia in the hybrid surubim (Pseudoplatystoma corruscans $x$ Pseudoplatystoma fasciatum) caused by Aeromonas hydrophila. Aquaculture Research, v.43, p.908-916, 2012. DOI: 10.1111/j.1 3652109.2011.02905.x.

SUZER, C.; ÇOBAN, D.; KAMACI, H.O.; SAKA, S.; FIRAT, K.; OTGUCUOĞLU, Ö.; KÜÇÜKSARI, H. Lactobacillus spp. bacteria as probiotics in gilthead sea bream (Sparus aurata, L.) larvae: effects on growth performance and digestive enzyme activities. Journal of Aquaculture, v.280, p.140-145, 2008. DOI: 10.1016/j.aquaculture.2008.04.020.

TOURNAS, V.; STACK, M.E.; MISLIVEC, P.B.; KOCH, H.A.; BANDLER, R. Yeast, molds and mycotoxins. In: U. S. FOOD AND DRUG ADMINISTRATION. Bacteriological analytical manual. 2001. Available at: <http://www.fda.gov/Food/ FoodScienceResearch/LaboratoryMethods/ucm071435.htm>. Accessed on: 23 Mar. 2013.

VERSCHUERE, L.; ROMBAUT, G.; SORGELOOS, P.; VERSTRAETE, W. Probiotic bacteria as biological control agents in aquaculture. Microbiology and Molecular Biology Reviews, v.64, p.655-671, 2000. DOI: 10.1128/MMBR.64.4.655671.2000.

VIEIRA, F.N.; BUGLIONE, C.C.; MOURIÑO, J.P.L.; JATOBÁ, A.; MARTINS, M.L.; SCHLEDER, D.D.; ANDREATTA, E.R.; BARRACO, M.A.; VINATEA, L.A. Effect of probiotic supplemented diet on marine shrimp survival after challenge with Vibrio harveyi. Arquivo Brasileiro de Medicina Veterinária e Zootecnia, v.62, p.631-638, 2010. DOI: 10.1590/ S010209352010000300019. 
WANG, Y.B.; TIAN, Z.Q.; YAO, J.T.; LI, W. Effect of probiotics, Enteroccus faecium, on tilapia (Oreochromis niloticus) growth performance and immune response. Aquaculture, v.277, p.203207, 2008. DOI: 10.1016/j.aquaculture.2008.03.007.

WANG, Y.B.; XU, Z.R. Effect of probiotics for common carp (Cyprinus carpio) based on growth performance and digestive enzyme activities. Animal Feed Science and Technology, v.127, p.283-292, 2006. DOI: 10.1016/j.anifeedsci.2005.09.003.

ZIEMER, C.J.; GIBSON, G.R. An overview of probiotics, prebiotics and synbiotics in the functional food concept: perspectives and future strategies. International Dairy Journal, v.8, p.473-479, 1998. DOI: 10.1016/S09586946(98)000715.

$\overline{\text { Recebido em } 31 \text { de agosto de } 2011 \text { e aprovado em } 17 \text { de maio de } 2013}$ 